Vol. 5, No. 1, 2020

\title{
MODELING OF OPERATIONAL CONTROL OF THE OXYGEN REGIME OF THE AQUATIC ECOSYSTEM IN THE CONDITIONS OF THE DNIEPER BASIN
}

\author{
Roman Ponomarenko ${ }^{1}$, Leonid Plyatsuk ${ }^{2}$, Oleg Tretyakov ${ }^{3}$, Irina Ablieieva ${ }^{2}$ \\ ${ }^{1}$ National University of Civil Defence of Ukraine, \\ 94, Chernyshevska Str., Kharkiv, 61023, Ukraine \\ ${ }^{2}$ Sumy State University, \\ 2, Rymskoho-Korsakova Str., Sumy, 40007, Ukraine \\ ${ }^{3}$ Kharkiv State Academy of Physical Education, \\ 99, Klochkivska Str, Kharkiv, 61058, Ukraine \\ prv@nuczu.edu.ua
}

https://doi.org/10.23939/ep2020.01.058

Received: 10.02 .2020

(C) Ponomarenko R., Plyatsuk L., Tretyakov O., Ablieieva I., 2020

\begin{abstract}
The article investigates the adequacy of the mathematical model of oxygen regime prediction in the Dnieper basin, based on the classic Streiter-Phelps model. Retrospective analysis of the Dnieper oxygen parameters with further verification of the StreeterPhelps model adequacy for the Dnieper basin conditions was used. The mathematical model of the dynamics of the integral indices of the ecological state of the reservoir (the Streeter-Phelps model) has been improved by supplementing the corrective coefficients, which allows predicting with sufficient accuracy the change of the Dnieper ecological state.
\end{abstract}

Key words: Dnieper basin, ecological state, anthropogenic load, quality assessment, quality forecast.

\section{Introduction}

Continuous human activity constantly leads to a deterioration of water quality and environmental flow of river runoff. The issue of protecting river basins, and in particular their rational use, is the most pressing issue of today, directly related to the health of the nation as a whole.

The issue of real-time water quality is of paramount importance. Systematic analysis of the current environmental state of the Dnieper basin and the organization of management and protection of its water resources allows to identify a number of the most urgent problems that need to be addressed.

It is difficult to overestimate the importance of the Dnieper basin waters in providing Ukraine's water resources, since almost $80 \%$ of the economic water supply in Ukraine, which accounts for two thirds of the country's population of about 30 million people, belongs to the Dnieper waters. On its shores are located more than fifty major cities and industrial centers, in particular the capital of Ukraine - Kiev, which determines its national significance for the country $[1,2,3]$.

In $[2,3,4]$ the main characteristics of the Dnieper basin that determine its ecological state were considered. A retrospective analysis of the water quality of the Dnipro River was carried out according to the monitoring demand of Ukraine's water resources over the last 10 years (difference of total anion content, $\mathrm{PO}_{4}{ }^{3-}$ phosphate ions, $\mathrm{NH}_{4}{ }^{+}$ammonium ions, biochemical oxygen demand $\left(\mathrm{BOD}_{5}\right)$ ratio to dissolved oxygen (DO) concentration), and possible causes of surface water quality change were identified.

Based on the analysis [3, 4], the aquatic ecosystem of the Dnieper River, as the main aquatic artery of Ukraine, being under constant technogenic influence, tends to permanently and steadily deteriorate its ecological state.

In the future, changing the ecological state of the surface waters of the Dnieper basin in the direction of its improvement cannot occur without the development and implementation of a reliable and effective model for predicting its ecological state.

The solution to the complex problem of the Dnieper basin environmental rehabilitation should be taken to a new level in accordance with the radical changes in the nature of nature management and development strategy 
of the country's economy, and only by developing a national program of restoration of its ecological state.

Today, substantive reviews on the prediction and analysis of dissolved oxygen content and biochemical oxygen demand are reported in $[5,6,7,8]$.

Two-component predictive models of the ecological state of water have become quite widespread, where the processes of formation of water quality are estimated by the demand of oxygen (processes of biochemical oxidation of organic compounds) and its receipt (the process of atmospheric aeration).

Some differences are noted in the prediction of water quality: a return to classic models in which the concentration of dissolved oxygen is a function of the decay of dissolved organic matter and natural processes (atmospheric aeration). The DO-BOD relationship is described by the classic Streeter-Phelps model, whose equations of processes based on first-order kinetics assumptions were analytically solved by Phelps and Streeter for a river section, and are now quite widely used in calculations [6, 7].

Meaning that, it is advisable to determine the adequacy of the mathematical model for the prediction of oxygen regime conditions in the Dnieper basin on the basis of the classic Streeter-Phelps model, taking into account the data of a retrospective analysis of its oxygen indices.

\section{Materials and Methods}

The purpose of the article is to determine the adequacy of the predictive mathematical model for predicting oxygen regime (BOD and DO) in the Dnieper basin on the basis of the classic Streeter-Phelps model.

To achieve this goal, it is necessary to solve the following problems:

- carrying out a retrospective analysis of the data of oxygen indicators of the Dnieper;
- verification of the adequacy of the Streeter-Phelps model for the conditions of the Dnieper basin.

A retrospective analysis of the water quality was carried out according to the water sampling samples of the Dnipro River within the Basin Water Resources Management Department for 12 posts [3].

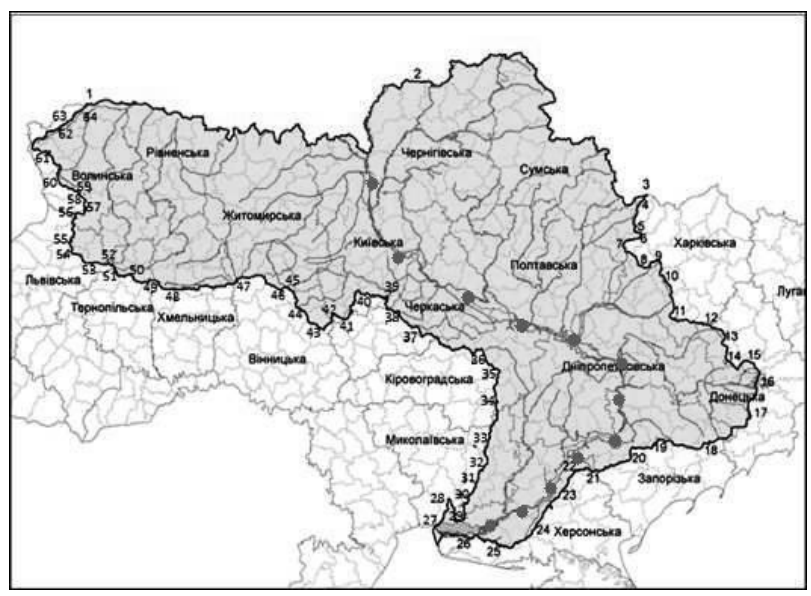

Fig. 1. Schematic location of 12 water intake control posts, according to which a retrospective analysis of the data of the Dnieper oxygen indicators was carried out

Investigations of the oxygen regime of surface waters of the Dnieper basin were conducted by retrospective analysis of monitoring data and environmental assessment of water resources of Ukraine by the State Water Resources Agency of Ukraine, taking into account the requirements of regulatory documents $[9,10]$ for the period from January 2013 to January 2018 (for $\mathrm{BOD}_{5}$ ) and from January 2015 to January 2018 (for $\mathrm{DO})$.

\section{Results and Discussion}

The initial data for the study are given in table 1,2 .

Table 1

Average annual values of dissolved oxygen $\left(\mathrm{mg} / \mathrm{dm}^{3}\right)$ at water intake posts of the Dnieper basin

\begin{tabular}{|l|l|l|l|l|l|l|l|l|l|l|l|l|}
\hline Years & P1 & P2 & P3 & P4 & P5 & P6 & P7 & P8 & P9 & P10 & P11 & P12 \\
\hline 2013 & - & - & - & - & - & - & - & - & - & - & - & - \\
\hline 2014 & - & - & - & - & - & - & - & - & - & - & - & - \\
\hline 2015 & 9.68 & 7.80 & 7.80 & 9.20 & 8.85 & 9.95 & 10.19 & 8.34 & 8.25 & 8.00 & 10.46 & 8.00 \\
\hline 2016 & 9.53 & 7.45 & 9.53 & 7.57 & 9.01 & 9.47 & 9.46 & 8.30 & 7.87 & 9.20 & 10.63 & 9.20 \\
\hline 2017 & 8.68 & 6.75 & 8.25 & 7.58 & 7.79 & 9.10 & 8.74 & 8.64 & 8.00 & 9.23 & 10.35 & 9.23 \\
\hline 2018 & 8.83 & 8.82 & 9.05 & 8.79 & 8.96 & 8.78 & 8.48 & 8.50 & 7.40 & 8.53 & 9.53 & 8.53 \\
\hline
\end{tabular}


Table 2

Average annual values of BOD $\left(\mathrm{mg} / \mathrm{dm}^{3}\right)$ at water intake posts of the Dnieper basin

\begin{tabular}{|l|l|l|l|l|l|l|l|l|l|l|l|l|}
\hline Years & P1 & P2 & P3 & P4 & P5 & P6 & P7 & P8 & P9 & P10 & P11 & P12 \\
\hline 2013 & 2.0 & 2.7 & 4.2 & 2.6 & 2.6 & 2.0 & 2.3 & 2.6 & 2.8 & 1.3 & 1.4 & 1.3 \\
\hline 2014 & 2.9 & 3.6 & 2.4 & 2.4 & 3.6 & 2.1 & 2.4 & 2.9 & 2.8 & 1.4 & 1.3 & 1.4 \\
\hline 2015 & 4.0 & 3.6 & 3.1 & 2.1 & 4.5 & 1.8 & 2.0 & 2.9 & 2.8 & 1.5 & 1.2 & 1.5 \\
\hline 2016 & 4.3 & 4.2 & 3.3 & 2.1 & 3.9 & 2.4 & 2.4 & 2.6 & 2.9 & 1.6 & 1.3 & 1.6 \\
\hline 2017 & 3.0 & 5.9 & 2.9 & 2.4 & 4.0 & 2.4 & 2.5 & 3.1 & 3.0 & 1.3 & 1.2 & 1.3 \\
\hline 2018 & 2.4 & 6.0 & 2.4 & 2.0 & 3.5 & 2.2 & 2.4 & 3.1 & 3.5 & 2.0 & 1.5 & 2.0 \\
\hline
\end{tabular}

The internal structure of the model of interaction between DO and BOD is determined by the set of $\{\mathrm{S} 1\}$ functions of DO demand and the set of $\{\mathrm{S} 2\}$ functions of production / demand of BOD. The arguments of each function included in $\{\mathrm{S} 1\}$ and $\{\mathrm{S} 2\}$ are DO and BOD (which, in turn, are functions of coordinates and time), as well as their derivatives and environmental factors, functions of third-party sources and effluents of DO and BOD [6,7].

On the basis of [8] it is obvious that the decisive influence on the whole evolution of the DO and BOD models was caused by the classic study of Streeter and Phelps. The paper assumes that the balance between the concentrations of DO and BOD depends only on two processes: re-flow and demand of DO during oxidation (or decay) of BOD, i.e.

$$
\begin{gathered}
\left\{S_{l}\right\}=\left\{-k_{l} x_{l}\right\} \\
\left\{S_{2}\right\}=\left\{k_{2}\left(C_{s}-x_{2}\right)-k_{l} x_{1}\right\}
\end{gathered}
$$

where $x_{1}-\mathrm{BOD}_{5}$ concentration, $\mathrm{mg} / \mathrm{dm}^{3} ; \quad x_{2}-$ DO concentration, $\mathrm{mg} / \mathrm{dm}^{3} ; \quad C_{s}-\mathrm{DO}$ saturation concentration, $\mathrm{mg} / \mathrm{dm}^{3} ; k_{l}-\mathrm{BOD}_{5}$ decay rate constant (mineralization coefficient), $1 / \mathrm{sec} ; k_{2}$ - reaeration rate constant for DO, $1 / \mathrm{sec}$.

After taking into account the conditions for simplification (stationarity of the water flow, functions $S_{1}$ and $S_{2}$ for all river points and uniformity of distribution $x_{1}, x_{2}$ along the cross section), i.e. $x_{1}=x x(\mathrm{z}$, $\mathrm{t}), x_{2}=x_{2}(\mathrm{z}, \mathrm{t})$, where $\mathrm{z}$ is the distance from the source of discharge along the river bed, $t$ is time, and the independent variables $\mathrm{z}$ and $\mathrm{t}$ are related to each other by a simple relation: $\mathrm{z}=\mathrm{ut}$ (here and is the velocity of the flow), the Streeter-Phelps model is reduced to the system of ordinary differential equations, and takes the following form:

$$
\left\{\begin{array}{l}
u \frac{d x_{1}}{d z}=-k_{1} x_{1} \\
\frac{d x_{2}}{d t}=u \frac{d x_{2}}{d z}=k_{2}\left(C_{s}-x_{2}\right)-k_{2} x_{2} .
\end{array}\right.
$$

The solution of this system of equations is as follows:

$$
\left\{\begin{array}{l}
x_{1}=x_{1,0} e^{-k_{1} z / u}+C_{1} ; \\
x_{2}=x_{2,0} e^{-k_{2} z / u}+C_{S}\left(1-e^{-k_{2} z / u}\right)+\frac{k_{1}}{k_{2}-k_{1}} x_{1,0}\left(e^{-k_{2} z / u}-e^{-k_{1} z / u}\right)+C_{2} ;
\end{array}\right.
$$

where $x_{1,0}, x_{2,0}$ - concentration respectively in the start point, $\mathrm{mg} / \mathrm{dm}^{3} ; C_{l}, C_{2}$ - the corrective coefficients introduced to improve the accuracy of the forecast.

$$
\begin{gathered}
C_{1}=f(G M) \\
C_{2}=f(C O D / B O D)
\end{gathered}
$$

where $f(G M)$ - function of the total anion content; $f(C O D / B O D)$ - function that determines the ratio of $\mathrm{BOD}_{5}$ to DO.

It can be seen, far from the discharge point $\lim _{t \rightarrow \infty} x_{1}=0$ , that is, water purifies itself from active impurities, and, $\lim _{t \rightarrow \infty} x_{2}=C_{s}$, that is, water is saturated with oxygen.

The factors $x_{1,0}$ and $x_{2,0}-$ in equations (3) are determined experimentally, the coefficients $k_{1}$ and $k_{2}$ are unknown.

The coefficients of mineralization $k_{1}$ and reaeration $k_{2}$ can be found experimentally by the formulas:

$$
\begin{gathered}
k_{1}=t^{-1} \cdot \ln \frac{x_{1,0}}{x_{1}} . \\
k_{2}=\frac{x_{1,0} \cdot k_{1} \cdot e^{-k_{1} t}}{x_{2}} .
\end{gathered}
$$

The change in dissolved oxygen content in the Dnieper water by annual average is shown in Fig. 2 .

The graph (Fig. 2) shows a clear tendency towards a decrease of dissolved oxygen in the Dnieper water, which indicates a significant deterioration of the oxygen regime of the aquatic ecosystem of the Dnieper basin due to the significant anthropogenic load on its water, which is confirmed by previous studies [3].

The trends of changes in the $\mathrm{BOD}_{5}$ content in the Dnieper water by annual average are shown in Fig. 3. 


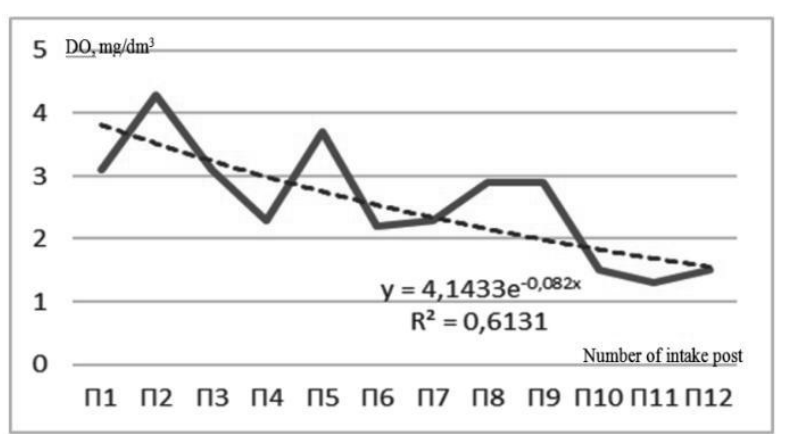

Fig. 2. Changes in dissolved oxygen content $\left(\mathrm{mg} / \mathrm{dm}^{3}\right)$ in Dnieper water by annual average 2015-2018

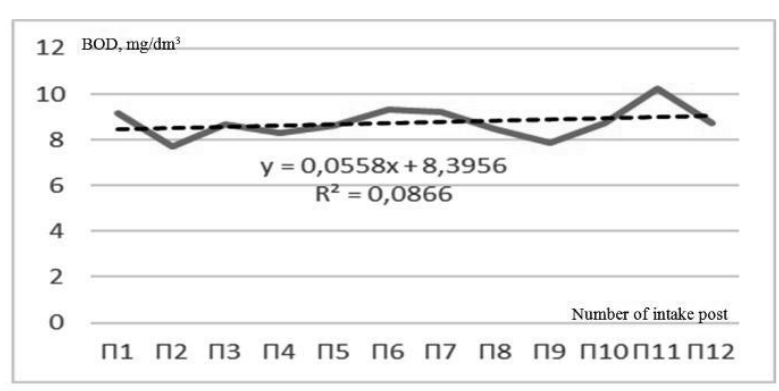

Fig. 3. Changes in BOD content $\left(\mathrm{mg} / \mathrm{dm}^{3}\right)$ in the Dnieper water by annual average 2013-2018

Just as in the case of dissolved oxygen, the graph shows a tendency for an increase in $\mathrm{BOD}_{5}$ in the Dnieper water, which is also explained by an increase in anthropogenic load on the reservoir, which is also confirmed by previous studies [3].

The analysis of long-term results of observation of the environmental state of the Dnieper allowed us to establish that the corrective factor $\mathrm{C} 1$ (4) depends on the total content of anions in water by law:

$$
\mathrm{C}_{1}=-0.0002 \mathrm{c}_{1}^{2}+0.2719 \mathrm{c}_{1}-81.922 \text {, }
$$

where $\mathrm{C}_{1}-\triangle \mathrm{BOD}_{5}$ (difference of $\mathrm{BOD}_{5}$ above and below the discharge point), $\mathrm{mg} / \mathrm{m}^{3} ; \mathrm{c}_{1}$ - the total content of anions, $\mathrm{mg} / \mathrm{m}^{3}$.

The analysis of long-term results of monitoring the environmental state of the Dnieper allowed us to establish that the corrective factor $\mathrm{C} 2$ (5) depends on $\mathrm{BOD}_{5} / \mathrm{DO}$ in the form

$$
\mathrm{C}_{2}=-0.5542 \mathrm{c}_{2}^{2}-0.561 \mathrm{c}_{2}+2.871
$$

where $\mathrm{C}_{2}-\triangle \mathrm{DO}$ (difference of DO above and below the discharge point), $\mathrm{mg} / \mathrm{m}^{3} ; \mathrm{c}_{2}$ - ratio $\mathrm{BOD}_{5} / \mathrm{DO}$.

Thus, with the actual data of observations of the environmental state of the water body, it becomes possible to calculate the parameters of the indicator (signal) indicators (DO- BOD), depending on the values of the anion content and the ratio of $\mathrm{BOD}_{5} / \mathrm{DO}$.

The introduction of the corrective coefficients $\mathrm{C}_{1}$ and $\mathrm{C}_{2}$ can significantly improve the reliability of the prediction of the ecological state of water surface water source using the proposed mathematical model, which guarantees the high adequacy of operational decisions of water resources management.

To determine the parameters of the model of the oxygen regime of the Dnieper, i.e. the values of the coefficients $\mathrm{k}_{1}$ (coefficient of biochemical oxidation of organic substances) and $\mathrm{k}_{2}$ (coefficient of reactivity), we use the data of tables 1-2 and calculated by formulas (6) and (7). The table 3 shows the values of the coefficients $\mathrm{k}_{1}$ and $\mathrm{k}_{2}$.

Table 3

\section{Calculated values of the coefficients $k_{1}$ and $k_{2}$}

\begin{tabular}{|l|c|c|}
\hline Post & $\mathbf{k}_{\mathbf{1}}$ & $\mathbf{k}_{\mathbf{2}}$ \\
\hline P1 & -0.001667 & 0.00350 \\
\hline P2 & 0.001725 & 0.00783 \\
\hline P3 & 0.001525 & -0.01254 \\
\hline P4 & -0.002432 & -0.01493 \\
\hline P5 & 0.002658 & 0.01451 \\
\hline P6 & -0.000369 & 0.00740 \\
\hline P7 & -0.001034 & 0.00311 \\
\hline P8 & -0.000150 & 0.00076 \\
\hline P9 & 0.003318 & 0.01135 \\
\hline P10 & 0.000740 & 0.00075 \\
\hline P11 & -0.000740 & 0.00064 \\
\hline P12 & 0.001061 & 0.0053 \\
\hline
\end{tabular}

Thus, the raw data for the calculation of the coefficients $k_{1}$ and $k_{2}$ are the average annual values of the corresponding oxygen regime indicators for the period 2013-2018.

On the basis of the calculated coefficients $\mathrm{k}_{1}$ and $\mathrm{k}_{2}$, the model values of $\mathrm{BOD}_{5}$ and the dissolved oxygen deficit were calculated. Checking the adequacy of the $\mathrm{BOD}_{5}$ and DO model is shown in the relevant graphs (Figs. 4 and 5), which show the curves of the average $\mathrm{BOD}_{5}$ and DO for 2018, the values modeled on the classic Streeter-Phelps model, with values obtained from taking into account the corrective coefficients.

The correlation coefficient between the model value of $\mathrm{BOD}_{5}$ and the actual value (Fig. 4) is 0.76 , and between the actual value and model using the corrective factor -0.94 , which can be considered acceptable given the experience of previous researchers [6,7], which point to the fact that all models proposed to describe the interaction of DO and $\mathrm{BOD}_{5}$ are affected by the fact that all parameters of this model obtained from the experiment are inaccurate (the error can be as high as $40 \%$ ).

The result of simulation of dissolved oxygen values (Fig. 5) shows a high correlation coefficient -0.85 ; for the classic model it is 0.71 .

The advantages of the proposed approach are the ability to easily and promptly process the available monitoring data of the surface water source. Using the proposed model allows you to make calculations without the use of special computer programs and profile skills. 


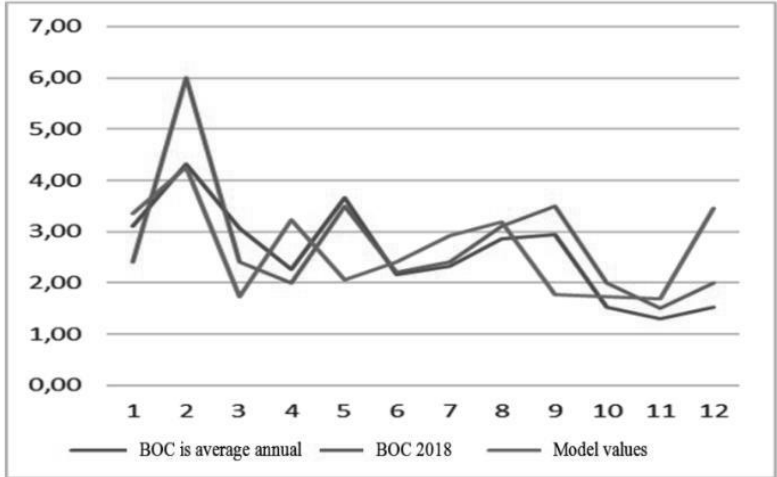

Fig. 4. Dynamics of simulated, average and actual (2018) BOD5 values $\left(\mathrm{mg} / \mathrm{dm}^{3}\right)$

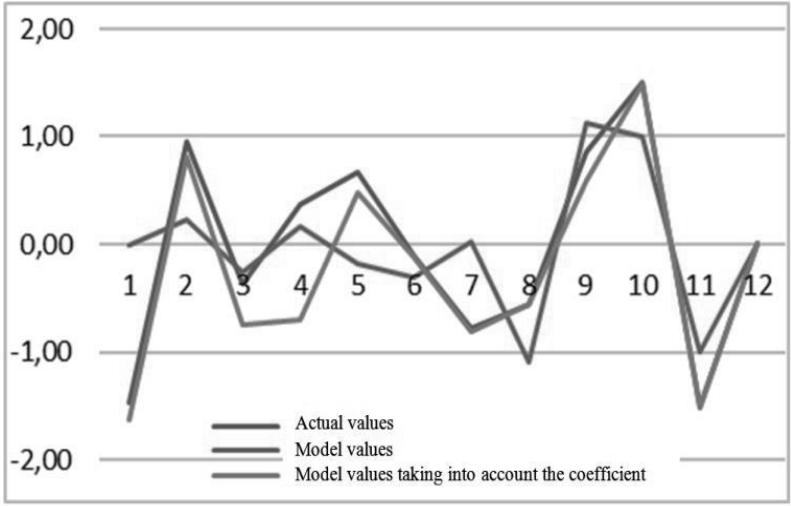

Fig. 5. Dynamics of simulated and actual (2018) dissolved oxygen values $\left(\mathrm{mg} / \mathrm{dm}^{3}\right)$

As a disadvantage, however, it will be fair to point out the limitations of the components of the model, which may possibly be the subject of further research in the direction of determining operational methods of controlling the ecological state of the surface source. If the goal of our research is to be achieved, the application of the proposed model is justified.

The main purpose of the obtained model is to forecast BIA and dissolved oxygen deficiency based on the results of operational monitoring.

\section{Conclusion}

On the basis of the retrospective analysis for 20132018 , the analysis of changes in the $\mathrm{BOD}_{5}$ and $\mathrm{DO}$ indicators in the Dnieper water was performed according to 12 sampling posts. Trends in the deterioration of the oxygen regime of the river have been identified - a decrease in the concentration of dissolved oxygen and an increase in $\mathrm{BOD}_{5}$ by annual average. This can be explained by the increase in anthropogenic load on the reservoir pool. The mathematical model of the dynamics of the integral indices of the ecological state of the reservoir (the Streeter-Phelps model) has been improved by supplementing the corrective coefficients, which allows to predict with sufficient accuracy the change of the ecological state of the surface source, including in the conditions of the water ecosystem of the Dnieper basin. The parameters $\mathrm{k}_{1}$ (coefficient of biochemical oxidation of organic substances) and $\mathrm{k}_{2}$ (coefficient of reaeration) of the Streeter-Phelps model for the water conditions of the Dnieper basin were calculated.

\section{References}

[1] Marynych O. M., Shyshchenko P. H.: Physical Geography of Ukraine, Textbook. K.: Znannia, 2005.

[2] Savchuk D.: Ecolog. Bulletin, 2003, 5-6, 24.

[3] Ponomarenko R. V., Plyatsuk L. D., Tretyakov O. V., Kovalov P. A.: Scientific and technical journal "Technogenic and ecological safety", 2019, 6 (2), 69.

[4] Bezsonnyi V., Tretyakov O., Khalmuradov B., Ponomarenko R.: Eastern-European Journal of Enterprise Technologies. 2017, 5/10 (89), 32. http://repositsc.nuczu.edu.ua/handle/123456789/5546

[5] Bezsonnyi V., Tretyakov O., Kravchuk A. M., Statsenko Yu. F.: Construction, material science, mechanical engineering: Coll. of sciences. wash. Series: Life Safety. DVNZ "Pridnepr. state. Academy of Construction and Architecture"; under the general editorship of V.I. Bolshakov. Dnipro, 2016, 93, 113.

[6] Mokin B. I. Mokin V. B., Mokin O. B.: Mathematical methods for the identification of dynamic systems: a textbook. Vinnitsa: VNTU, 2010.

[7] Rohalev A. N.: Materials of the XIV Conference with International Participation: Institute of Computational Technologies, Siberian Branch of the Russian Academy of Sciences 2012,101.

[8] Tretyakov O. V., Bezsonnyi V. L., Ponomarenko R. V., Borodych P. Iu.: Emergency Problems: A Scientific Journal. 2019, 29, 61.

http://repositsc.nuczu.edu.ua/bitstream/123456789/8881/1/\% D0\%9F\%D0\%9D\%D0\%A1\%201_2019.pdf

[9] Map of Monitoring and Environmental Assessment of Water Resources of Ukraine. State Agency for Water Resources of Ukraine. http://monitoring.davr. gov.ua/EcoWaterMon/GDKMap/Index

[10] DSTU 4808:2007. Sources of centralized drinking water supply. Hygienic and environmental requirements for water quality and selection rules: enforced by the order of the State Consumer Standard of Ukraine from 05.07.07 p. №144. Official edition. K. : State Consumer Standard of Ukraine, 2007. 39 p. 